(둥 (ㄱ)

PROSIDING

SEMINAR NASIONAL

FKIP 2018

"Dunia Pendidikan dalam Perubahan Revolusi 4.0" 13 Oktober 2018
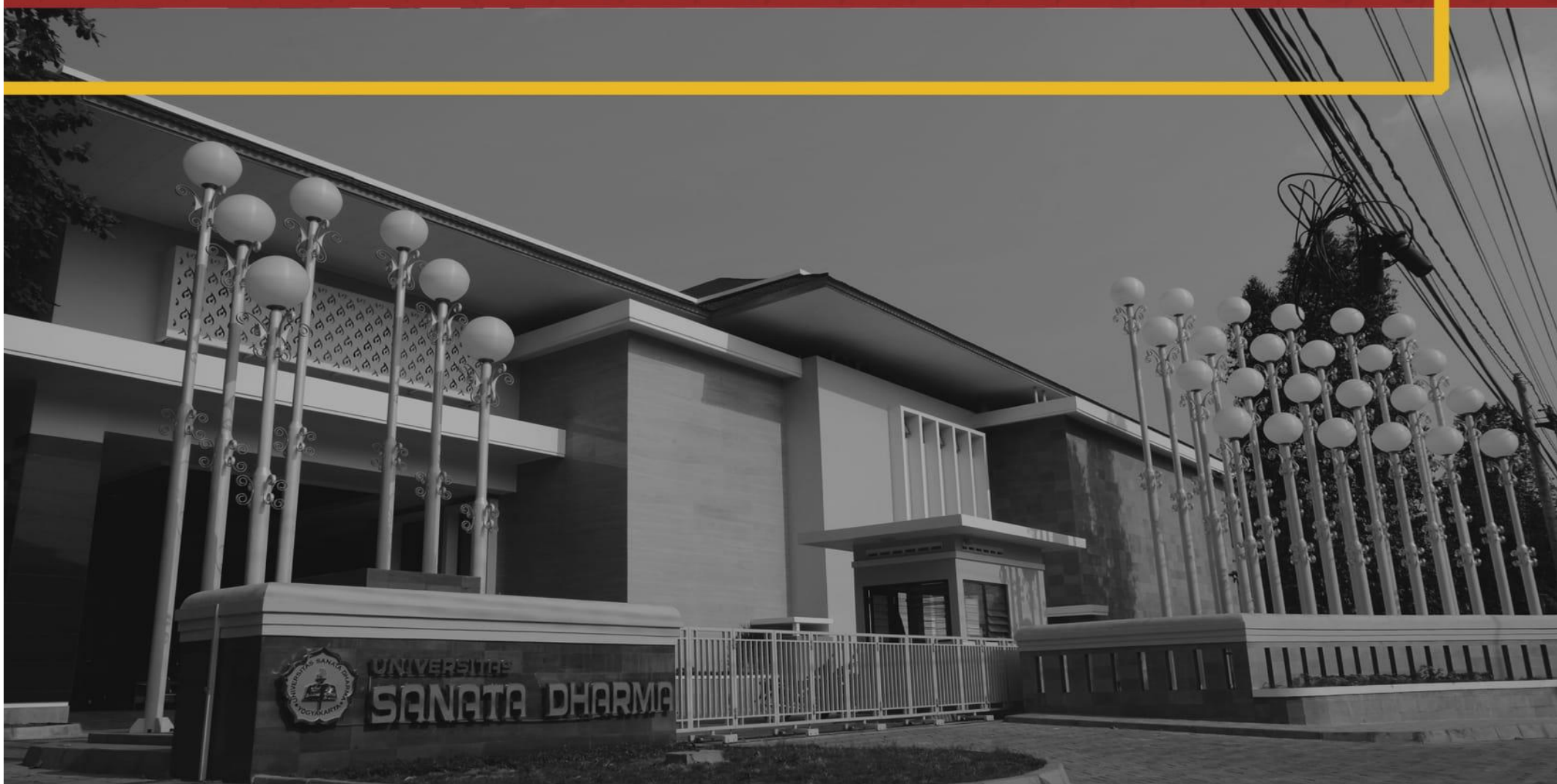

FAKULTAS KEGURUAN DAN ILMU PENDIDIKAN UNIVERSITAS SANATA DHARMA 2018 


\title{
PROSIDING
}

\section{Seminar Nasional FKIP 2018}

"Dunia Pendidikan dalam Perubahan Revolusi 4.0"

\author{
Universitas Sanata Dharma \\ 13 Oktober 2018
}

\begin{abstract}
Kontributor:
Aan Suryana, Agnes Putri Wiraswasti, Andes Sugiarto, Andri Anugrahana, Apri Damai Sagita Krissandi, Aria Putra, Ariadi Nugraha, B A Indriasari, Benediktus, Febrianto, Brigida Intan Printina, C. Teguh Dalyono, Caraka Putra Bhakti, Christiyanti Aprinastuti, Christophorus Putro Damringtyas, Diah Ervina Lailil Ulum, Dini Restiyanti Pratiwi, Dwi Agustina, Eko, Emilia Nurpirasari,

Fileksius Gulo, Fransiskus Ivan Gunawan, Gracesila Adevia, Haniek Sri Pratini, Hari Kusmanto, Ignatius Bondan Suratno, Irine Kurniastuti, Kelik Agung Cahya Setiawan, Khansa Salsabila, Khoirul Huda, Kristiani Olivia Rasi, Kurnia Martikasari, Laurensia Aptik Evanjeli, Lucius Pravasta Alver Leryan, Maria Nikkita Mega Melati, Mario Priyo Hutomo, Miraniatman Gulo, Nicholas Adven Christiyanto, Nova Irawati Simatupang, Novi Triana Habsari, Nuni Nurajizah, Nurhilda Rahmadhani,

Olivia Prisandra, Palupi Sri Wijayanti, Pungki Revianti, Retna Widyaningsih,

Retno Handayani, Septiyana Rohmawati, Shinta Sugiarto, St Fatimah Azzahra, St. Suwarsono, Tresiana Sari Diah Utami, Tri Probo, Vinsentia Dini, Wike Nurani, Yadi Kusmayadi, Yosia Pamardi
\end{abstract}

\section{Editor:}

Barli Bram dan Patricia Angelina

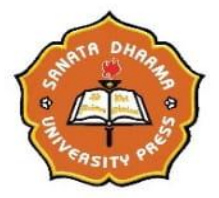

SANATA DHARMA UNIVERSITY PRESS 


\section{PROSIDING}

\section{Seminar Nasional FKIP 2018}

\section{"Dunia Pendidikan dalam Perubahan Revolusi 4.0"}

\section{Universitas Sanata Dharma, 13 Oktober 2018}

Copyright $(\odot) 2018$

Fakultas Keguruan dan IImu Pendidikan, Universitas Sanata Dharma
Editor:
Barli Bram
Patricia Angelina
Reviewer:
Paulus Suparno
Yohanes Harsoyo
Markus Budiraharjo
Andy Rudhito
Teguh Dalyono
Yuliana Setyaningsih
FX Ouda Teda Ena
Hendra Kurniawan

Buku Elektronik e-Book:

ISBN: 978-602-5607-82-0

EAN: 9-786025-607820

Layout:

Tutur Nur Utami

Yohana Dian R

Anselmo Stevin L

Cetakan Pertama, 2018

vi; 325 hlm.; $21 \times 29,7 \mathrm{~cm}$.

Sabtu, 13 Oktober 2018

Universitas Sanata Dharma

Yogyakarta

PENERBIT:

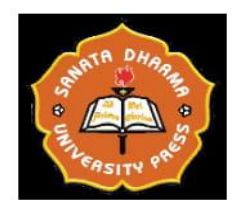

SANATA DHARMA UNIVERSITY PRESS

Lt. 1 Gedung Perpustakaan USD

Jl. Affandi (Gejayan) Mrican,

Yogyakarta 55281

Telpon: (0274) 513301, 515253;

Ext.1527/1513; Fax (0274) 562383

Email: publisher@usd.ac.id
Ketua

Juster Donal Sinaga

Sekretaris:

Prias Hayu Purbaning Tyas

Bendahara:

Brigida Intan Printina

Elisabeth Dian Atmajati

Divisi Acara:

Maria Agustina Amelia

Yuseva Ariyani Iswandari

Mega Wulandari

Divisi Perlengkapan:

Nicolas Bayu Kristiawan

Bernardinus Agus Arswimba

Divisi Transportasi:

Danang Satria Nugraha

Arif Budi Prasetyo

Divisi Publikasi \& Dokumentasi

Apri Damai Sagita Krissandi

Agustinus Sariyanta

Divisi Prosiding

Barli Bram

Patricia Angelina Lasut

Divisi Konsumsi

Agnes Lusia Budi Asri

Chatarina Artilantari

SPONSOR PENYELENGGARA:

FKIP UNIVERSITAS SANATA DHARMA

Jl. Affandi, Catur Tunggal Depok,

Sleman, Yogyakarta

Website: www.usd.ac.id/fakultas/pendidikan
SOGANG UNIVERSITY

35 Baekbeom-ro, Daeheung-dong, Mapogu, Seoul, South Korea

Website: wwwe.sogang.ac.kr

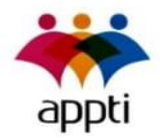

Sanata Dharma University Press anggota APPTI (Asosiasi Penerbit Perguruan Tinggi Indonesia)

Hak Cipta Dilindungi Undang-Undang.

Dilarang memperbanyak karya tulis ini dalam bentuk dan dengan cara apa pun, termasuk fotokopi, tanpa izin tertulis dari penerbit.

Isi prosiding sepenuhnya menjadi tanggungjawab penulis. 



\section{PENGANTAR}

Kementerian Riset, Teknologi dan Pendidikan Tinggi (Kemenristekdikti) Republik Indonesia telah menyusun rekomendasi Pengembangan Iptek Dikti dalam menghadapi Revolusi Industri 4.0 dalam berbagai hal, misalnya kelembagaan, bidang studi, kurikulum, sumber daya, serta pengembangan cyber university, risbang dan inovasi. Senada dengan itu, Universitas Sanata Dharma telah menjadikan isu tersebut sebagai salah satu isu strategis yang tertuang dalam Renstra USD 2018-2022, yaitu sistem pendidikan yang tanggap zaman. Artinya, USD perlu meningkatkan relevansi dan keunggulan program studi yang sesuai dengan tuntutan zaman. Secara khusus, Fakultas Keguruan dan Ilmu Pendidikannya merasa penting menganggapi isu-isu tersebut.

Ada panggilan yang cukup kuat untuk menyiapkan diri menghadapi era tersebut. Perubahan paradigm harus segera dilakukan. Perubahan tersebut pertama-tema terhadap padangan akan kompetensi-kompetensi yang diperlukan oleh lapangan di era digital, manajemen pendidikan, sistem kelola pendidikan, dan metode pembelajaran. Salah satu bentuk respon FKIP USD terhadap perubahan ini adalah melakukan sharing gagasan tentang perubahan ini melalui Seminar Nasional Fakultas Keguruan dan Ilmu Pendidikan (SNFKIP) 2018, yang diselenggarakan Sabtu, 13 Oktober 2018 di Auditorium Driyarkara Universistas Sanata Dharma. Prosiding SNFKIP 2018 ini memuat 28 naskah yang ditulis oleh para pemakalah.

Tim Editor 


\section{DAFTAR ISI}

PENGANTAR

PENGARUH KEPEMIMPINAN TRANSFORMASIONAL KEPALA SEKOLAH, LINGKUNGAN KERJA DAN BUDAYA SEKOLAH TERHADAP KINERJA GURU DI SEKOLAH MENENGAH ATAS KOTA WATES DALAM MENGHADAPI REVOLUSI INDUSTRI 4.0

Andes Sugiarto dan Kurnia Martikasari

PERSIAPAN GURU SEKOLAH DASAR YANG PROFESIONAL DALAM MENGHADAPI GENERASI DIGITAL

Andri Anugrahana

MODUL LATIHAN DASAR ORGANISASI DAN LATIHAN DASAR KEPEMIMPINAN

BAGI MAHASISWA

Ariadi Nugraha, Khansa Salsabila dan Wike Nurani

PENENTUAN HASIL BELAJAR PSIKOMOTOR DENGAN MENGGUNAKAN TEKNIK PENILAIAN KINERJA PADA MATA PELAJARAN PENDIDIKAN JASMANI, OLAHRAGA DAN KESEHATAN

B A Indriasari.....

STRATEGI LAYANAN DASAR BERBASIS LOCAL WISDOM UNTUK MENINGKATKAN KEMAMPUAN CRITICAL THINKING SISWA DI ERA REVOLUSI 4.0

Bayu Selo Aji, Muhammad A. N. Ghiffari dan Cucu Kurniasih 34

"MONEM": EDUCATIONAL GAMES TO INTRODUCE BASIC ECONOMIC CONCEPTS TO ELEMENTARY STUDENTS

Benediktus Febrianto.

MEDIA TO EXPLORE DIPONEGORO CHARACTERS BASED ON THEORY CONE OF EDGAR DALE'S EXPERIENCE

Brigida Intan Printina

IMPLEMENTASI PENDIDIKAN KARAKTER RELIGIUS

DI SMP MUHAMMADIYAH 1 KARTASURA

Diah Ervina Lailil Ulum dan Hari Kusmanto .....

MODEL INTERNSHIP PROGRAM BERBASIS LITERASI DIGITAL BAGI CALON PENDIDIK MENGHADAPI REVOLUSI INDUSTRI 4.0

Emilia Nurpirasari, Nuni Nurajizah dan Caraka Putra Bhakti.

TEORI DEKONSTRUKSI DAN DEKONSTRUKSI TEORI: STRATEGI PEMBELAJARAN ALTERNATIF PADA TEORI-TEORI SEJARAH KONTROVERSIAL PERISTIWA 1965

Fileksius Gulo 
Prosiding Seminar Nasional FKIP 2018, Desember 2018

PROSIDING

Seminar Nasional FKIP 2018

http:// usd.ac.id/snfkip2018

Universitas Sanata Dharma, Yogyakarta, Indonesia

\title{
MEDIA TO EXPLORE DIPONEGORO CHARACTERS BASED ON THEORY CONE OF EDGAR DALE'S EXPERIENCE
}

\author{
Brigida Intan Printina \\ Universitas Sanata Dharma \\ intanbrigida@usd.ac.id \\ DOI: doi.org/10.24071/snfkip.2018.07 \\ diterima 9 Oktober 2018; diterbitkan 21 Desember 2018
}

\begin{abstract}
This article aims to illustrate the use of several media to explore the character of Diponegoro from Edgar Dale Experience Cone. Media to explore Indonesian hero characters, is very important to respond to the changes in Revolution 4.0 because using the media of student learning easily absorbs abstract things into concrete as described by Edgar Dale's theory. This article uses descriptive qualitative methods to illustrate the use of several historical and media learning media in accordance with Edgar Dale's theory, specifically to discuss the character of Diponegoro. The results of this study serve to strengthen the character of the nation's children, so that with the existing technological advances do not change their identity and identity as a culture-rich nation. The hope is that historical educators can innovate with learning media that is adapted to contextual history learning to deal with changes in Revolution 4.0.
\end{abstract}

Keywords: Diponegoro, history learning, Revolution 4.0

\section{Pendahuluan}

Teknologi dalam belajar penggunaan media pembelajaran yang sesuai dengan materi dapat disajikan dengan harapan dapat meningkatkan minat dan motivasi peserta didik. Untuk itu kompetensi dan tujuan pembelajaran akan dapat dicapai dengan baik. Media pembelajaran ialah segala sesuatu yang digunakan untuk menyalurkan pesan serta dapat merangsang pikiran, perasaan, perhatian, dan kemauan peserta didik sehingga dapat mendorong terjadinya proses belajar memiliki tujuan. (Miarso, 2004;458).

Pada era revolusi industry 4.0 ini dibutuhkan perubahan dan pengembangan teknologi yang cepat dan tepat guna, apalagi dalam dunia pendidikan khususnya pendidikan sejarah. Perubahan dan pengembangan tersebut akan mengarahkan pada kemajuan setiap aspek kehidupan dan dimanfaatkan masyarakat secara luas. Akan tetapi, perubahan yang sangat cepat harus ditopang dengan kesiapan dalam berbagai bidang, salah satunya kesiapan (SDM) ang memiliki bekal mengawal perkembangan teknologi masa depan.

Isnarto dalam Wacana SM 17 September 2018 mengatakan walaupun era baru ini menekankan pola digital economy, artificial intelegency, big data, robotic, atau dikenal dengan fenomena distruptif, peran manusia sangatlah penting. Artinya, segala yang berjalan secara cepat akan lebih baik jika dikawal 
tempat itu diantaranya Pondok Pesantren Gading, Grojogan, Sewon, Wonokromo, Jejeran, Turi, dan Pulo.Diponegoro juga berkelana ke tempat keramat oleh wangsa Mataram (Imogiri, Gua Surocolo, Gua Secang, Pamancingan/Mancingan, Parangtritis, dan Parangkusumo). Kepedulian terhadap roh leluhur ini dimakna bahwa setiap orang bisa membersihkan diri dari pamrih sekaligus guna membenarkan gagasannya melalui penampakan roh leluhur Jawa.

\section{Karakter yang Ditanam Sang Pangeran}

Diponegoro Juga senang menularkan kebiasaan untuk membuat gembira orang-orang di sekitarnya. Diponegoro mempunyai kebiasaan mengirimkan pakaukan perempuan kepada para panglimanya yang dianggap telah bertindak seperti pengecut, ini mengiaskan bahwa pakaian itu lebih baik daripada pakaian tempur Jawa yang mereka kenakan dalam perang.

Sebagai sejarawan besar Peter Carey telah menyumbangkan sebagian besar hiudpnya terhadap sejarah Indonesia, khususnya Sang Pahlawan besar Pangeran Diponegoro. Kurang lebih selama 40 tahun Peter Careymenggali kehiudpan Diponegoro. Beberapa karyanya diantaranya "Kuasa Ramalan: Pangeran Diponegoro dan Akhir Tatanan Lama di Jiwa, 1785-1855"

Penelitian Peter Carey dianugerahi Sanghyang Kamahayanikan oleh penyelenggara Borobudur Writers and Cultural Festival (BWCF) 2014 di kawasan Candi Borobudur, Kabupaten Magelang, Jawa Tengah. Peter Carey tertarik akan kisah heorik Pangeran Diponegoro bermula dari sebuah tugas yang harus ia kerjakan ketika duduk di bangku kuliah. Tugas tersebut menjadi syarat mendapat beasiswa untuk penelitian.

Peter Carey pun berpikir untuk membuat penelitian tentang Revolusi Perancis di sebuah daerah di Perancis. Namun, penelitian tentang Revolusi Perancis sudah banyak dilakukan oleh peneliti lainnya. Atas saran gurunya, Peter Carey lalu mengangkat judul penelitian tentang ekspansi kekuasaan Raja Perancis bernama Napoleon di tanah Jawa.

Peter Carey beranggapan bahwa apabila meneliti tentang kekuasaan Deandels yang membuka sistem pemerintahan baru maka topic tersebut akan meluas dan menjadi sejarah baru. Ini pesan dari gurunya.

Peter Carey lantas mulai melakukan berbagai observasi sampai kemudian menemukan kisah sosok pemuda Jawa yang gigih melakukan pemberontakan melawan kolonialisme Belanda sampai kekuasaan Deandels.

Peter Carey merasa jika tidak dimulai, sejarah Indonesia akan lenyap, seperti Sisingamangaraja yang dianggap sebagai mitos. Meski mengambil nama orang lain dan bergembira dengan orang tersebut, namun mereka harus bermukim di kampung halaman sendiri. Artinya, masyarakat Indonesia harus peduli dengan kondisi bangsa ini yang diterjang gelombang hebat budaya Barat. Pater Peter Carey dianggap mampu menjelaskan dunia batin atau dunia dalam Perang Diponegoro.

\section{Media sebagai transfer Penanaman Karakter}

Ada berbagai pengertian tentang media pembelajaran. Menurut susunan katanya, media pembelajaran terdiri dari dua kata, media dan pembelajarna. Rossi 
dan Breidle (1966:3) mengemukakan bahw amedia pembelajaran adalah seluruh alat dan bahan yang dapat digunakan untuk mencapai tujuan pendidikan seperti radio, televisi, buku, koran, majalah, dan sebagainya. Gerlach dan Eli (1980: 244) menyatakan: "A medium, conceived is any person, material or event that establishs condition which enable the learner to acquire knowledge, skill, attitude". Media menurut Heinich dan Ibrahim, yang dikutip oleh I Wayan Santyasa (2007; 3), merupakan bentuk jamak dari kata medium. Medium didefinisikan sebagai perantara atau pengantar terjadinya komunikasi dari pengirim menuju penerima. Media merupakan salah satu komponen komunikasi, yaitu sebagai pembawa pesan.

Pembelajaran didefinisikan sebagai komunikasi antara guru dengan peserta didik. I Wayan Santyasa $(2007 ; 3)$ mengemukakan bahwa proses pembelajaran mengandung lima komponen komunikasi yaitu, guru (komunikator), bahan pembelajaran, media pembelajaran. Peserta didik (komunikan), dan tujuan pembelajaran. Jadi, media pembelajaran adalah segala sesuatu yang dapat digunakan untuk menyalurkan pesan (bahan pembelajaran), sehingga dapat merangsang perhatian, minat, pikiran, dan perasaan didik dalam kegiatan belajar untuk mencapai tujuan belajar.

Media pembelajaran adalah suatu perangkat lunak (software) berisi pesan atau informasi yang biasanya disajikan dengan menggunakan peralatan, sedangkan peralatan atau perangkat keras (hardware) merupakan sarana untuk dapat menampilkan pesan yang terkandung dalam media tersebut (Arief Sadiman, dkk, 2006; 19). Media belajar diartikan oleh Oemar Hamalik (1994; 11) ialah Berbagai alat, metode,dan teknik yang digunakan dalam angka lebih mengefektifkan komunikasi dan interaksi antara guru dan peserta didik dalam proses pendidikan dan pengajaran di sekolah.

Istilah media lainnya dikemukakan oleh Sri Anitah (2008: 1), bahwa media pembelajaran berarti "sesuatu yang mengantarkan pesan pembelajaran antara pemberi pesan kepada penerima pesan”. Briggs dalam Sri Anitah (2008: 1) mengatakan bahwa media pembelajaran pada hakikatnya adalah peralatan fisik untuk membawakan atau menyempurnakan isi pembelajaran. Termasuk di dalamnya buku, videotape, slide suara, suara guru, tape recorder, modul atau salah satu komponen dari suatu sistem penyampaian. Gagne dalam Kosasih (2007: 10) mengartikan media pembelajaran merupakan berbagai jenis komponen dalam lingkungan peserta didik yang dapat merangsang peserta didik untuk belajar. 
Prosiding Seminar Nasional FKIP 2018, Desember 2018

\section{Ragam Media Pendukung}

Aplikasi Edraw Mind Map

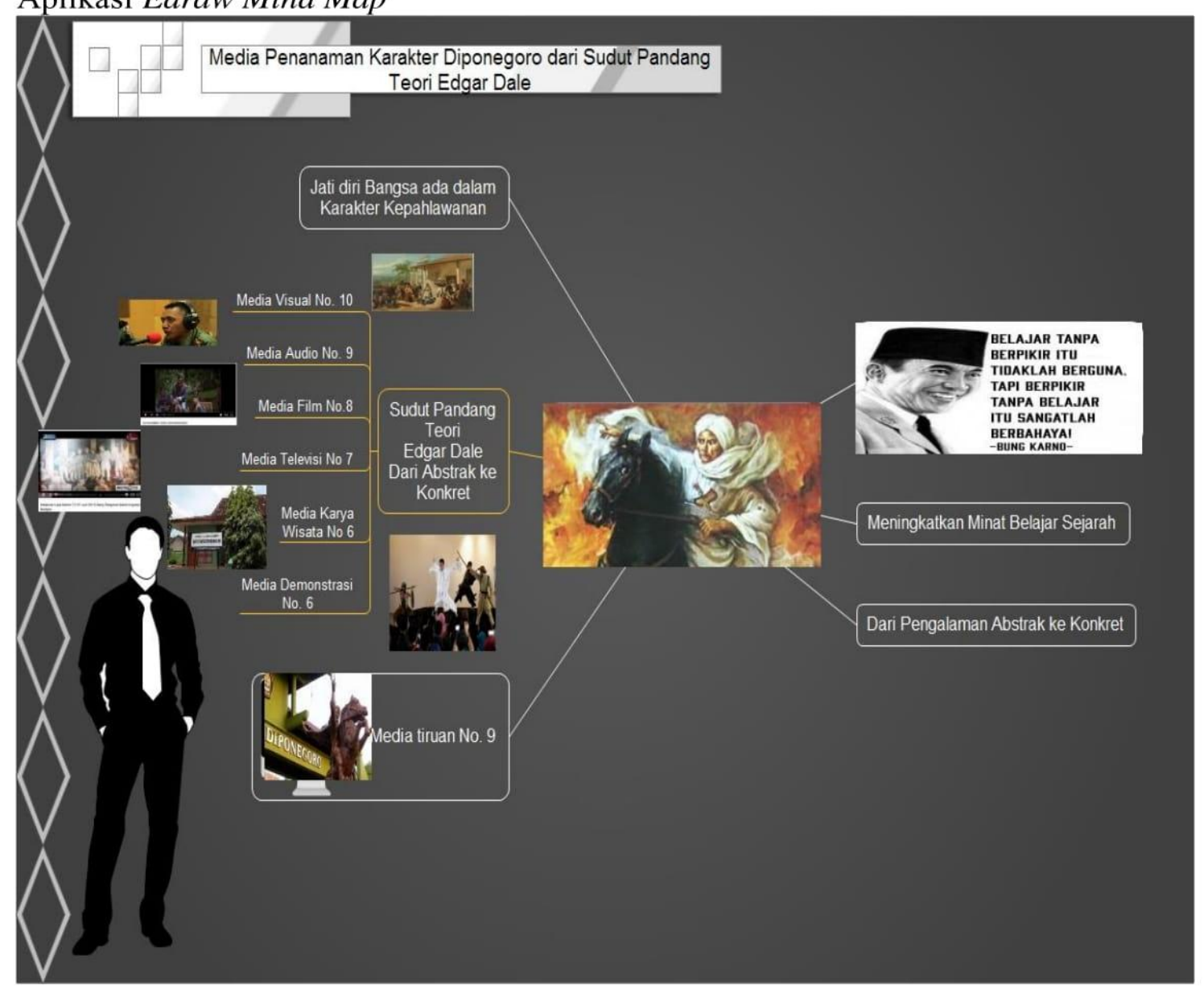

Aplikasi Edraw Mind Map dapat diunduh pada laman www.edrawsoft.com. Aplikasi ini menyerupai peta konsep yang penggunaanya hampir sama dengan penggunaan Microsoft Word, namun pada bagian toolbar ada banyak pilihan untuk mengkreasikan background untuk menarik minat pembaca. Pada tahapan ini, visualisasi dalam bentuk peta konsep menurut Edgar Dale menempati urutan ke tiga dan dapat digunakan di semua jenjang pendidikan. 


\section{Time Line menggunakan aplikasi Sutori}

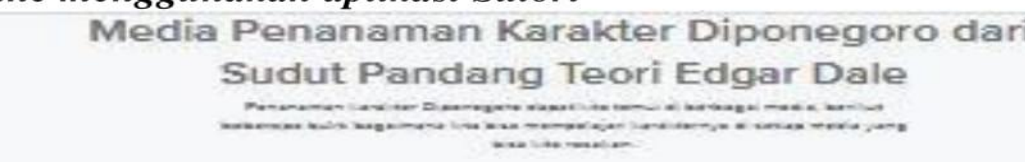

Ragam Medla Penanamen Karakter Diponegora dar1 Sudut Pandang Teort Edgar Dale
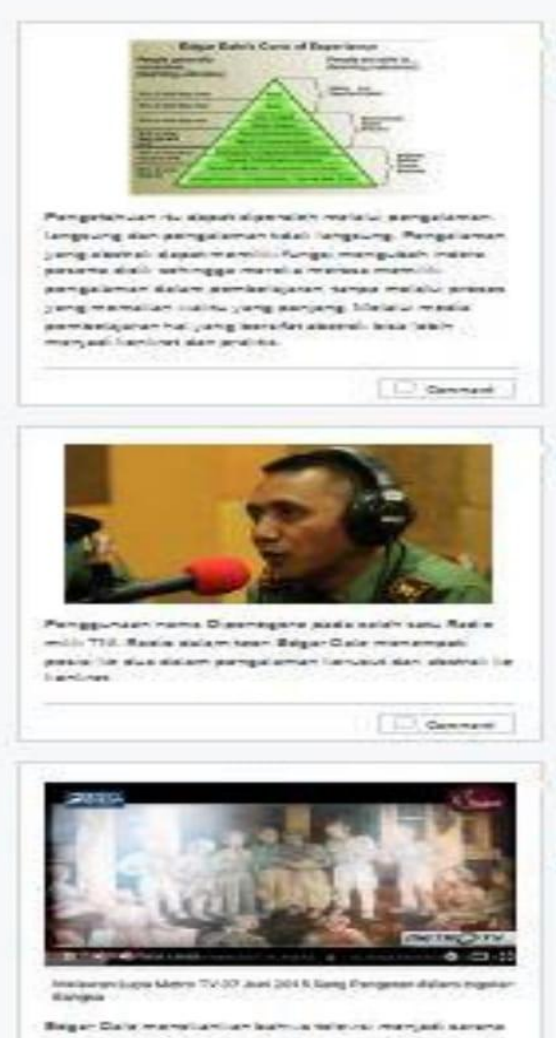
(20) -

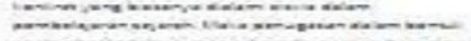

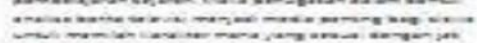
$-m$
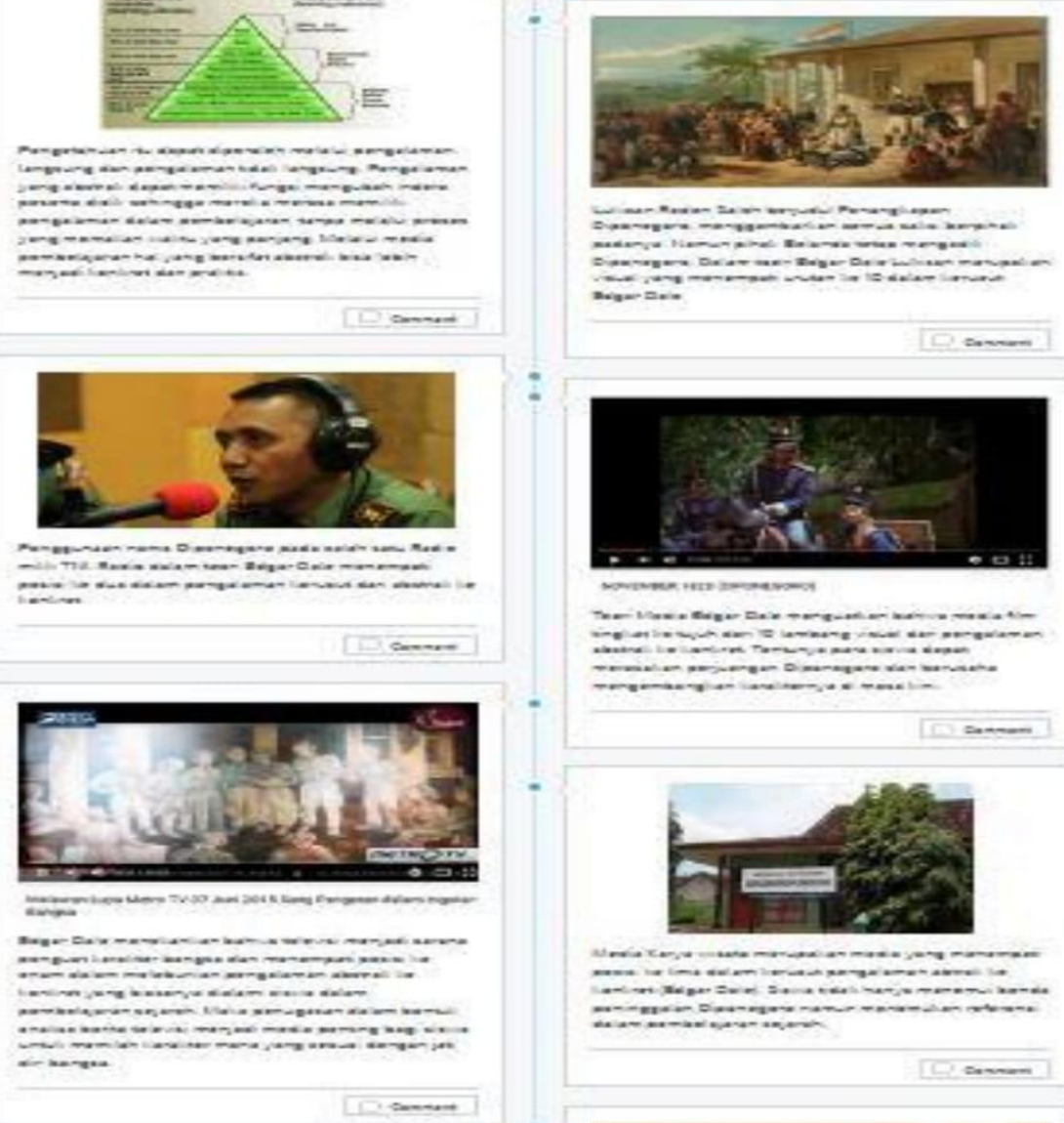
and (20)10$$
\text { Dand }
$$
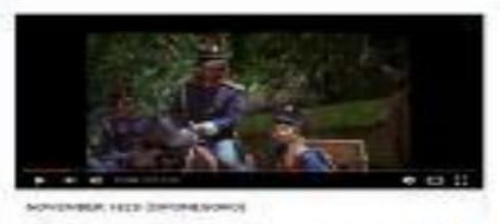

r. (1) -1.2. -

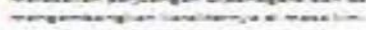

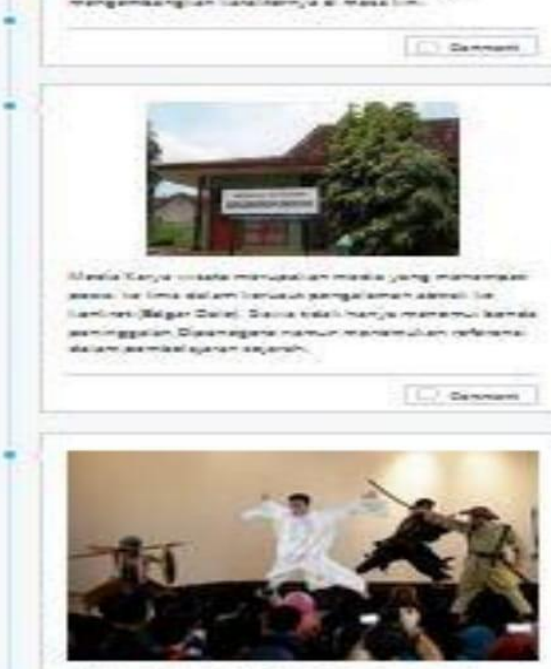

Aplikasi ini bisa didapatkan pada laman www.sutori.com, penggunaannya hampir sama dengan Edraw mind map, hanya penggambarannya berdasarkan urutan waktu (kronologi). Seperti yang ada di gambar menggambarkan bahwa media penanaman karakter Diponegoro bisa didapatkan di berbagai media dan semuan termasuk dalam teori pengalaman belajar abstrak ke konkret dari sudut pandang Edgar Dale. 
Prosiding Seminar Nasional FKIP 2018, Desember 2018

Media KOMIK DIGITAL Aplikasi Komik Toondo
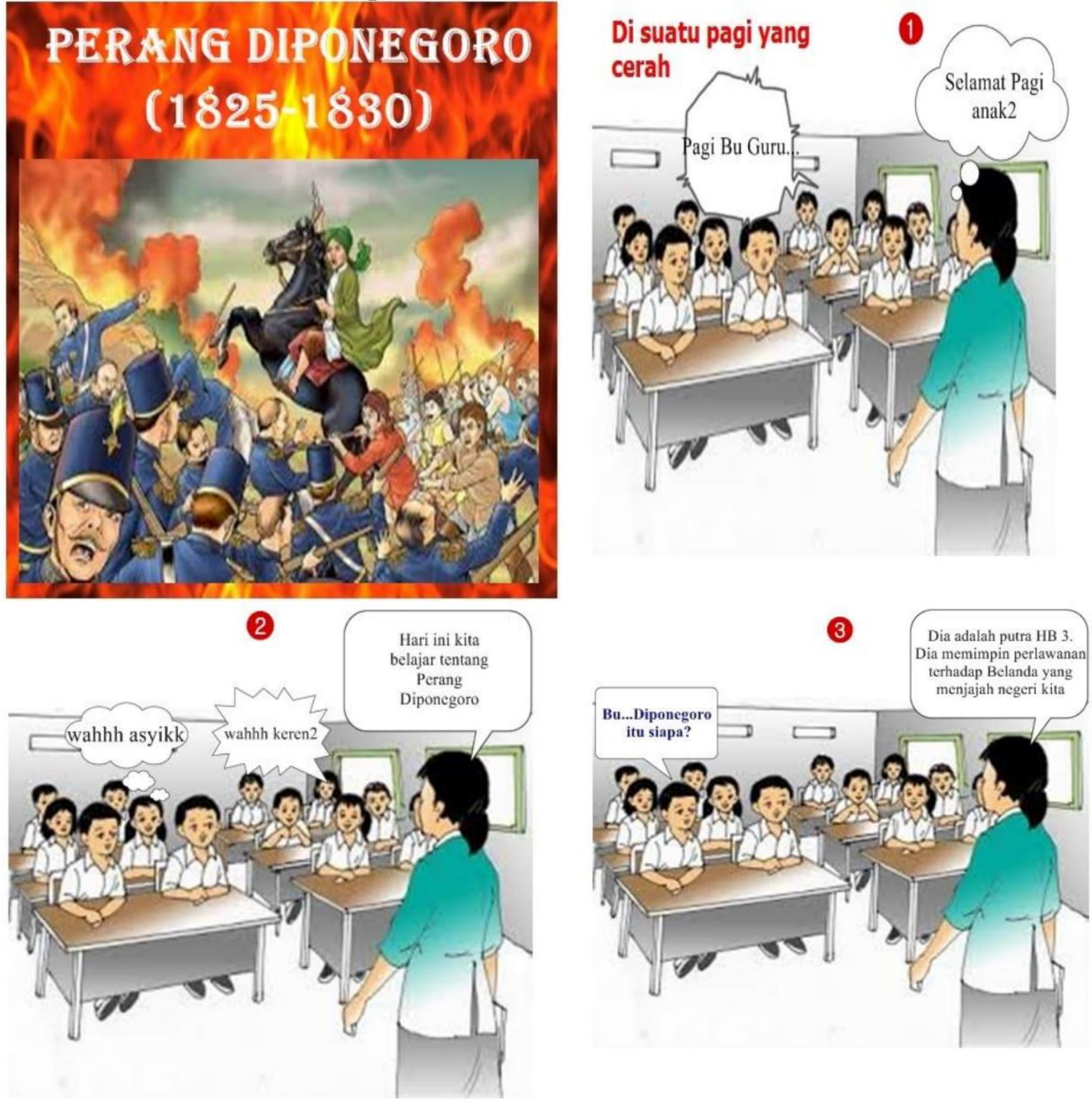
Prosiding Seminar Nasional FKIP 2018, Desember 2018

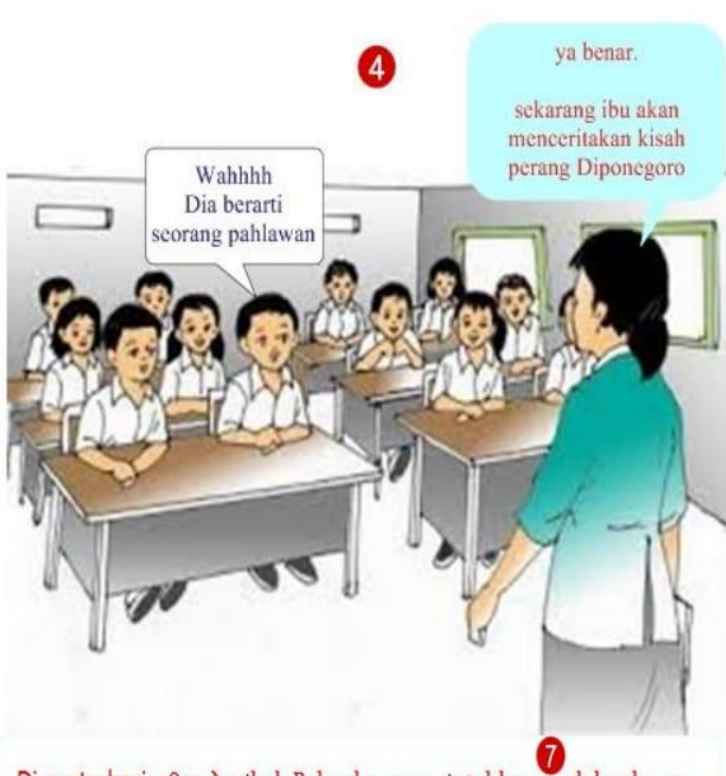

Di suatu hari, $1825 \rightarrow$ pihak Belanda memerintahkan anak buahnya untuk memasang anjir (pancang/ patok) dalam rangka membuat jalan baru. Pemasangan anjir ini secara sengaja melewati pekarangan milik Pangeran Diponegoro di Tegalrejo tanpa izin.

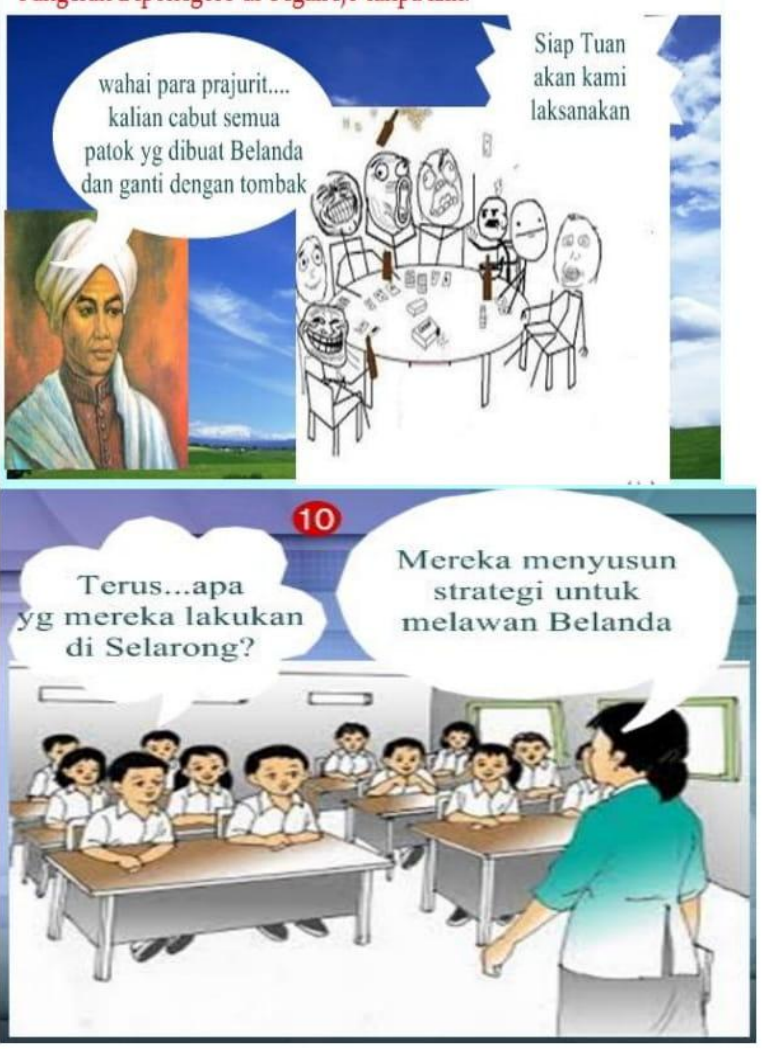

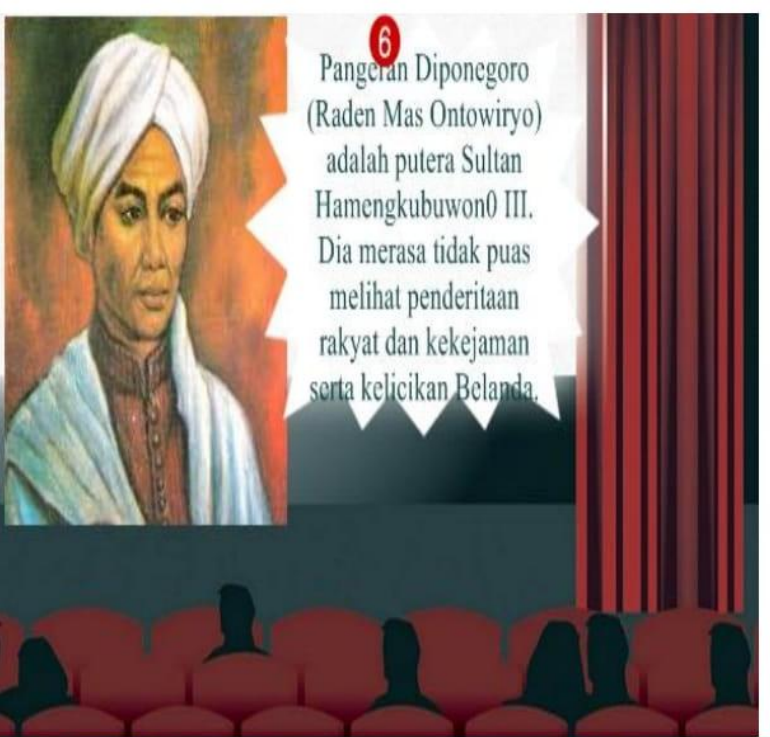

Pada tanggal 20 Juli 1825 sore hari, rakyat Tegalreja
berduyun-duyun berkumpul di ndalem
Tegalreja. Mereka membawa berbagai
senjata seperti pedang, tombak, dan lembing. Belanda mengetahuinya dan langsung menyerbu tempat itu
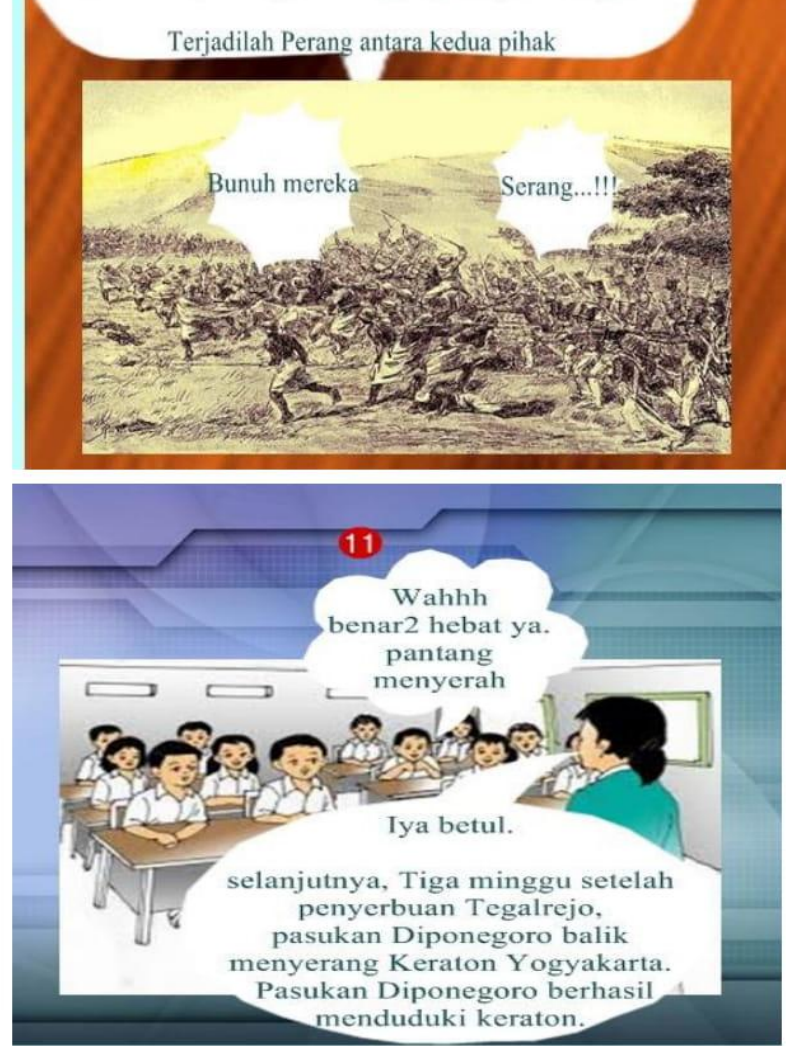


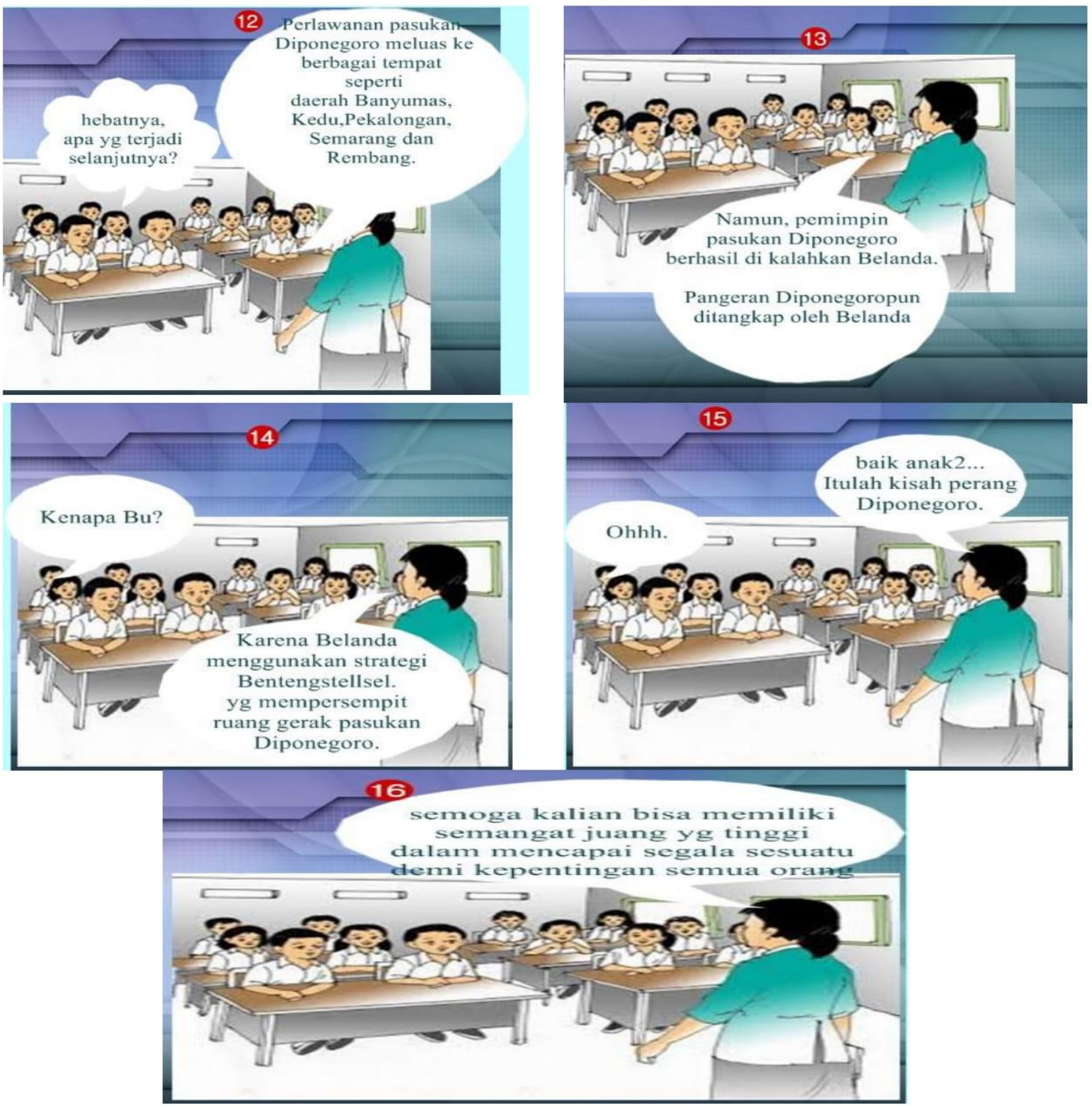

Media komik Digital bisa menggunaan berbagai aplikasi diantaranya, imeme, komik Toondo, Pixton, Marvels, dan masih banyak lagi. Para siswa dalam ruang kelas bisa diujicobakan membuat media ini sehingga pembelajaran sejarah menjadi terasa tidak membosankan. Siswa juga diajarkan untuk mencapai pembelajaran HOTS (High Order Thinking Skills).

Masih banyak media penanaman karakter lainnya yang dapat dimanfaatkan guru sejarah dengan waktu dan materi yang disesuaikan dengan kebutuhan setiap individu. Maka karakter para pahlawan termasuk Diponegoro akan lebih hidup 
dirasakan karena para siswa mengekspresikan sendiri karakter yang ada dalam pembelajaran sejarah.

\section{Penutup}

Pembelajaran Sejarah tanpa media dan model akan menjadi dangkal. Prof. Hermanu Joebagio dalam kuliah umum yang diselenggarakan di program studi Pendidikan Sejarah USD pada 21 September lalu menekankan bahwa para pemerhati dan pendidik sejarah dapat menggunakan mode of actuality untuk mengekspresikan memori kolektif bangsa yang saling berhubungan agar setiap generasi menemukan persatuan dalam keberagaman, sehingga mereka selalu dapat mengatakan kebenaran dan memperjuangkan karakter untuk kemajuan bangsa.

Dari persoalan dan pembahasan yang telah dipaparkan maka setiap guru atau pendidik sejarah mampu membiasakan diri dan mengintegerasikan pemanfaatan media pembelajaran secara optimal baik digital maupun non-digital. Pemerintah juga harus mengupayakan dukungan secra maksimal dengan program dan sarana yang matang di daerah apalagi SM3T. Pada akhirnya karakter bangsa dapat diimbangi dengan SDM yang siap menggunaakan teknologi yang kreatif demi kemajuan bangsa.

\section{Daftar Pustaka}

Amir, H. S. (1981). Media audio visual untuk pengajaran, penerangan, dan penyuluhan. Jakarta: PT. Gramedia.

Anitah, S. (2008). Strategi pembelajaran di SD. Jakarta: Universitas Terbuka.

Chatib, M. (2010). Gurunya manusia. Bandung: Kaifa.

Gerlach, V. S. \& Ely, D. P. (1971). Teaching \& media: A systematic approach (2nd ed.). Boston, MA: Allyn and Bacon.

Hamalik. (1994). Media pendidikan. Bandung: Citra Aditya Bakti.

Heri, P. (2012). Sisi lain Pangeran Diponegoro: Menimbang buku kuasa ramalan. Makalah disajikan dalam Seminar bedah buku Kuasa Ramalan: Pangeran Diponegoro dan Akhir Tatanan Lama di Jawa, 1785-1855 karangan Peter Carey, Balai Soedjatmoko Yogyakarta, 21 April 2012.

Roni, S. (2016). Perjuangan Pangeran Diponegoro: Antara nasionalisme, spiritualisme dan budaya. Yogyakarta: Patrapadi.

Rossi \& Breidle. (1966). Dalam Sanjaya (2008:204) Perencanaan dan desain sistem pembelajaran. Jakarta: Kencana.

Santyasa, I. W. (2007). Landasan konseptual media pembelajaran. Makalah. Universitas Pendidikan Ganesha.

Wina, S. (2006). Strategi pembelajaran. Jakarta: Kencana Prenada Media Group. 